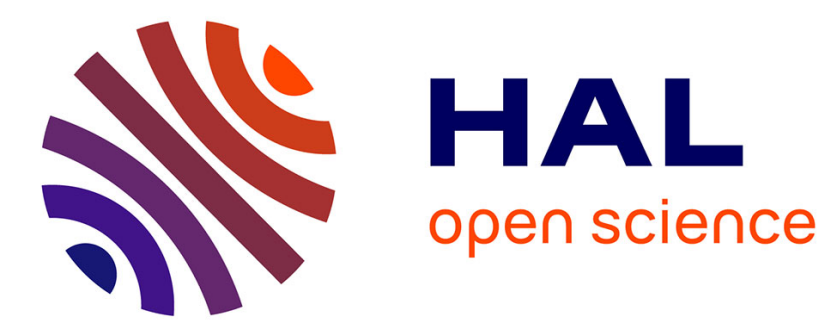

\title{
The Effect of the Trace Elements Additions on the Character of the Grain Boundary Population in High Purity $\alpha$-iron
}

\author{
M. Tacikowski, J. Le Coze, J. Driver, A. Kobylanski
}

\section{- To cite this version:}

M. Tacikowski, J. Le Coze, J. Driver, A. Kobylanski. The Effect of the Trace Elements Additions on the Character of the Grain Boundary Population in High Purity $\alpha$-iron. Journal de Physique IV Proceedings, 1995, 05 (C7), pp.C7-247-C7-253. 10.1051/jp4:1995728 . jpa-00254021

\section{HAL Id: jpa-00254021 https://hal.science/jpa-00254021}

Submitted on 1 Jan 1995

HAL is a multi-disciplinary open access archive for the deposit and dissemination of scientific research documents, whether they are published or not. The documents may come from teaching and research institutions in France or abroad, or from public or private research centers.
L'archive ouverte pluridisciplinaire HAL, est destinée au dépôt et à la diffusion de documents scientifiques de niveau recherche, publiés ou non, émanant des établissements d'enseignement et de recherche français ou étrangers, des laboratoires publics ou privés. 


\title{
The Effect of the Trace Elements Additions on the Character of the Grain Boundary Population in High Purity $\alpha$-iron
}

\author{
M. Tacikowski, J. Le Coze*, J. Driver* and A. Kobylanski* \\ Warsaw University of Technology, Department of Materials Science and Engineering, ul. Narbutta 85, \\ 02-524 Warszawa, Poland \\ * Ecole Nationale Supérieure des Mines de Saint-Etienne, Centre de Formation et de Recherche Science \\ des Matériaux et des structures, 158 Cours Fauriel, 42023 Saint-Etienne cedex 2, France
}

\begin{abstract}
The grain boundary misorientations and CSL frequencies in ultra high purity a-iron and iron doped with carbon (up to 200ppm) and sulphur (about 70ppm) have been determined by Electron Backscattered Diffraction to examine the effect of these elements on the character of the grain boundary population (CGBP). It was found that the binary Fe-S alloy exhibits a much higher fraction of low angle boundaries (LANGB) than iron and the other alloys, including the temary Fe-C-S alloy. The effect of the recrystallization annealing temperature on the CGBP has been also examined; the LANGB frequency decreases with increasing temperature. In the Fe-S alloy this effect is shifted towards a higher temperature range $\left(725-870^{\circ} \mathrm{C}\right)$. Also the initially high frequency of LANGB decreases with annealing time and resulting grain growth. The increased fraction of LANGB in the Fe-S alloy is interpreted as result of S reducing the rate of LANGB elimination, by a sulphur segregation dragging effect. The effect of $\mathrm{C}$ in the Fe-C-S alloy is attributed to the observed decrease of sulphur segregation to the grain boundaries.
\end{abstract}

\section{INTRODUCTION}

Watanabe and coworkers [1] and other authors [2] have shown that certain properties of polycrystalline materials are related to the grain boundary (GB) properties via the character of the grain boundary population (CGBP). For example, phenomena such as intergranular fracture are controlled by the frequency and the geometrical distribution of the random grain boundaries (RANDGB) [1,3]. On this basis Watanabe [4] proposed the idea of designing polycrystal properties by controlling the grain boundary population character. The relation between different features, concerning mainly the thermomechanical history of the material and the character of the grain boundary distribution - "CGBD" was examined. For this purpose the ECP technique was applied to the determination of "CGBD" by characterizing the frequency distribution of the grain boundary misorientations. However, with the exception of $[5,6]$, very little attention has been paid to the effect of the alloy chemical composition. In particular some kind of impurities or additions in the form of atom segregations or precipitation, even in low quantities, are known to strongly interact with the grain boundaries and affect their properties. In this work, we address the problem of sulphur and carbon trace additions in iron. Sulphur produces severe loss of ductility at room and high temperatures due to intergranular fracture [7-11]. The role played by this element is usually explained in terms of grain boundary weakening by the intergranular sulphide precipitates as well as by the sulphur atoms segregated on the grain boundaries. However, sulphur may also contribute to intergranular brittleness by changing the CGBP. For example, higher fractions of RANDGB, more susceptible to fracture, may be expected. Up till now this aspect was not investigated. On the other hand, carbon additions are known to reduce the detrimental effect of sulphur. Usually the ductility improvement is attributed to segregation competition between sulphur and carbon influencing the strength of the grain boundary cohesion $[8,12]$. However, one cannot exclude that carbon also acts by its influence on the CGBP. 
The aim of the present work, is to investigate the effect of carbon and sulphur on the CGBP in iron, using the Electron Backscatted Diffraction (EBSD) technique to determine the grain orientations developed by recrystallization. It should be emphasized that only the use of ultra high purity (UHP) iron doped with controlled quantities of carbon and sulphur can reveal the specific or combined effects of these elements. Synthetic alloys always contain residual impurities, which may mask the specific effect. For example, the hot brittleness of low carbon Al killed steels was previously attributed to the action of AlN precipitates. In fact brittleness appears when AIN is present with trace concentrations of sulphur (as low as 2 ppm) and only the use of UHP iron base alloys can reveal this effect [11].

\section{EXPERIMENTAL}

The UHP iron and the alloys were prepared in the Materials Centre of the Ecole des Mines de Saint-Etienne, the alloys by doping the UHP iron with controlled quantities of impurities by the method described in [13]. Three kinds of alloys were prepared: $\mathrm{Fe}-\mathrm{C}, \mathrm{Fe}-\mathrm{S}$ and $\mathrm{Fe}-\mathrm{C}-\mathrm{S}$ (Table 1) in order to separate the effects of the trace additions in the binary compositions and then to examine their combined effect in the ternary alloy. The samples were thermomechanically treated according to the schedule shown in the Fig.1. The second annealing, in the austenite range, was performed to reduce the texture resulting from the preceding stages of fabrication. Heat treatments were performed in vacuum-sealed the alloys; "HEX"-hydrostatic extrusion.

quartz ampoules in order to protect the samples against oxidation and contamination. Hydrostatic extrusion was used as a deformation method (triaxial compression state) to avoid fracture of the brittle $\mathrm{Fe}-\mathrm{S}$ alloy. The frequency distribution of the grain boundary misorientations was used to characterized the CGBP. The misorientation angles were determined on the cross section of samples for populations of 250 to 400 grain boundaries by the EBSD technique assisted by computer calculation [14]. The CGBPs, obtained after final recrystallization of the samples deformed up to $\mathrm{e}=1$. 1 , were compared as a function of the chemical composition (Table 1), temperature and time. Sulphur intergranular segregation was also examined by AES.

\begin{tabular}{|c|c|c|c|c|c|}
\hline ALLOY & $\begin{array}{l}\text { C content } \\
\text { [wt ppn] }\end{array}$ & $\begin{array}{l}S \text { content } \\
\text { [wi ppm] }\end{array}$ & $\begin{array}{c}\text { Strain/ } \\
\text { def mode }\end{array}$ & $\begin{array}{c}\text { Sample } \\
\mathrm{N}^{\mathrm{v}}\end{array}$ & $\begin{array}{l}\text { Annealing } \\
\text { Temp/time }\end{array}$ \\
\hline \multirow[t]{3}{*}{ UHP Fe } & \multirow[t]{3}{*}{$<10$} & \multirow[t]{3}{*}{$<10$} & \multirow[t]{3}{*}{ I.05/HEX } & 1 & $550^{\circ} \mathrm{C} / 1 \mathrm{~h}$ \\
\hline & & & & 2 & $600^{\circ} \mathrm{C} / 1 \mathrm{~h}$ \\
\hline & & & & 3 & $725^{\circ} \mathrm{C} / 1 \mathrm{~h}$ \\
\hline $\mathrm{Fe}-\mathrm{C}$ & 200 & $<10$ & 1.08/HEX & 4 & $725^{\circ} \mathrm{C} / 1 \mathrm{~h}$ \\
\hline \multirow[t]{4}{*}{$\mathrm{Fe}-\mathrm{S}$} & \multirow[t]{4}{*}{14} & \multirow[t]{4}{*}{71} & \multirow[t]{4}{*}{ 1.11/HEX } & 5 & $725^{\circ} \mathrm{C} / 1 \mathrm{~h}$ \\
\hline & & & & 6 & $820^{\circ} \mathrm{C} / \mathrm{hh}$ \\
\hline & & & & 7 & $870^{\circ} \mathrm{C} / 1 \mathrm{~h}$ \\
\hline & & & & 8 & $870^{\circ} \mathrm{C} / 10 \mathrm{~min}$ \\
\hline $\mathrm{Fe}-\mathrm{C}-\mathrm{S}$ & 153 & 74 & 1.08/HEX & 9 & $725^{\circ} \mathrm{C} / \mathrm{h} \mathrm{h}$ \\
\hline \multirow[t]{2}{*}{$\mathrm{Fe}-30 \mathrm{C}-\mathrm{S}$} & \multirow[t]{2}{*}{33} & \multirow[t]{2}{*}{65} & \multirow{2}{*}{$\begin{array}{c}1.10 t \\
\text { FORGING }\end{array}$} & 10 & $820^{\circ} \mathrm{C} / 1 \mathrm{~h}$ \\
\hline & & & & 11 & $870^{\circ} \mathrm{C} / 1 \mathrm{~h}$ \\
\hline
\end{tabular}

Table 1: Chemical composition and thermomechanical treatment of

\section{RESULTS}

\subsection{Microstructure}

The microstructures of the alloys obtained after the recrystallization annealing at $725{ }^{\circ} \mathrm{C}$ are shown in Fig. 2. The alloys exhibit different grain sizes after the same thermomechanical treatment. The grain size is refined by the presence of carbon and sulphur particularly when both are present, Fig. $2 \mathrm{~d}$. This grain refinement suggests a strong reduction of the grain boundary migration and inhibition of grain growth. The recrystallization stage is also probably slower. 

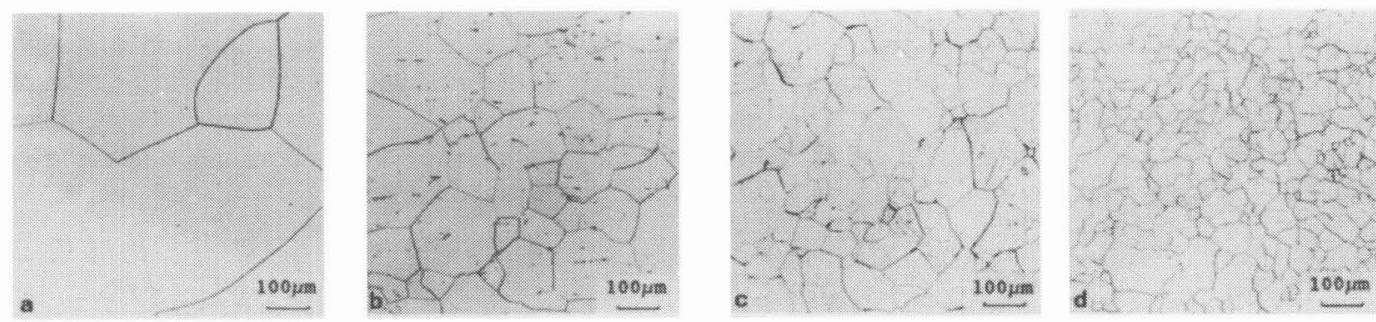

Figure 2: The microstructures after hydrostatic extrusion and recrystallization 1 h annealing at $725^{\circ} \mathrm{C}$ : a) $\mathrm{UHP}$ iron; b) $\mathrm{Fe}-\mathrm{C}$; c) $\mathrm{Fe}-\mathrm{S}$; d) $\mathrm{Fe}-\mathrm{C}-\mathrm{S}$.

\subsection{Character of the grain boundary population.}

\subsubsection{The effect of chemical composition}

The CGBPs resulting from the 1 hour recrystallization anneal at $725{ }^{\circ} \mathrm{C}$ are compared in Fig. 3 and Fig. 4 . At this temperature carbon is completely in solid solution but sulphur is partially precipitated (annealing at higher temperatures to dissolve sulphide precipitates is excluded because of the ferrite-austenite phase transformation). Obviously the trace additions influence the CGBP. The most important and clear effect is the addition of $70 \mathrm{ppm}$ of sulphur which increases the low angle boundary (LANGB) fraction almost by two. This effect disappears when about $150 \mathrm{ppm}$ of carbon is also present in the iron (Fe-C-S). No effect of carbon, present as the only addition to iron $(\mathrm{Fe}-\mathrm{C})$, was observed at $725^{\circ} \mathrm{C}$. As far as the coincidence site lattice grain boundary population (CSLGB) is concerned, it is difficult to compare the alloys with pure iron because of the relatively poor statistics for the iron sample (only $70 \mathrm{~GB}$ analyzed). However, one can notice that the CSLGB populations in Fe-C, Fe-S and Fe-C-S alloys are different. The total fraction of the CSLGB seems not to be significatively modified by the chemical composition Fig. 4 . As a consequence the lowest fraction of the RANDGB appears in the iron doped with sulphur. This result is rather surprising from the point of view of the interpretation of the role of sulphur in reducing brittleness, where the opposite effect could be expected.

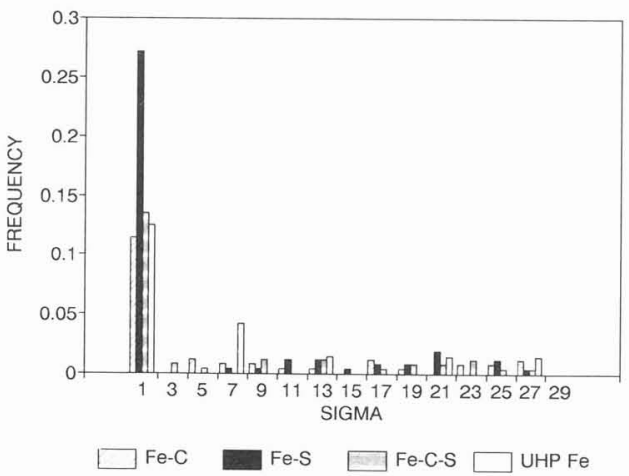

Figure 3: The distribution of the frequency of low angle ( 1$)$ and coincidence grain boundaries in UHP iron, Fe-S, $\mathrm{Fe}-\mathrm{C}$ and $\mathrm{Fe}-\mathrm{C}-\mathrm{S}$ alloys after hydrostatic extrusion and recrystallization annealing at $725^{\circ} \mathrm{C} / 1 \mathrm{~h}$.

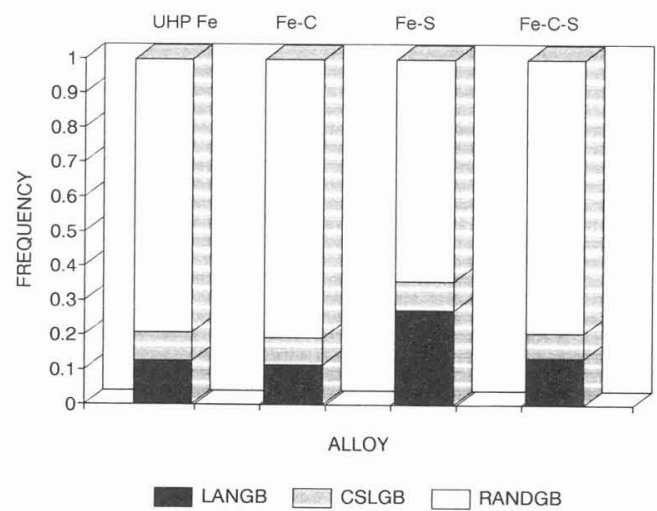

Figure 4: The frequency of the low angle, coincidence and random grain boundaries in the grain boundary population of UHP iron, $\mathrm{Fe}-\mathrm{S}, \mathrm{Fe}-\mathrm{C}$ and $\mathrm{Fe}-\mathrm{C}-\mathrm{S}$ alloys after hydrostatic extrusion and recrystallization annealing at $725^{\circ} \mathrm{C} / 1 \mathrm{~h}$

\subsubsection{The effect of temperature and time}

The effect of annealing temperature on the CGBP was also examined for pure iron and iron doped with sulphur, Fig.5. The aim was to establish how parameters other than the chemical composition influence the CGBP and also to clarify the mechanism of the trace addition effect on the CGBP. After lower recrystallization annealing temperatures $\left(550-600^{\circ} \mathrm{C}\right)$ the fraction of LANGB in pure iron attains the 
values almost as high as those of the $\mathrm{Fe}-\mathrm{S}$ alloy at $725^{\circ} \mathrm{C}$. In both cases the proportion of LANGB decreases with increasing temperature Fig. 5 , but the curve for iron doped with sulphur, is shifted towards a higher temperature range $\left(725-870^{\circ} \mathrm{C}\right)$. The fraction of LANGB also depends on the annealing time as shown in Fig. 6 for the Fe-S alloy. Even at the highest temperatures, for short annealing times, the Fe-S alloy exhibits a high fraction of LANGB, which decreases for longer treatments.

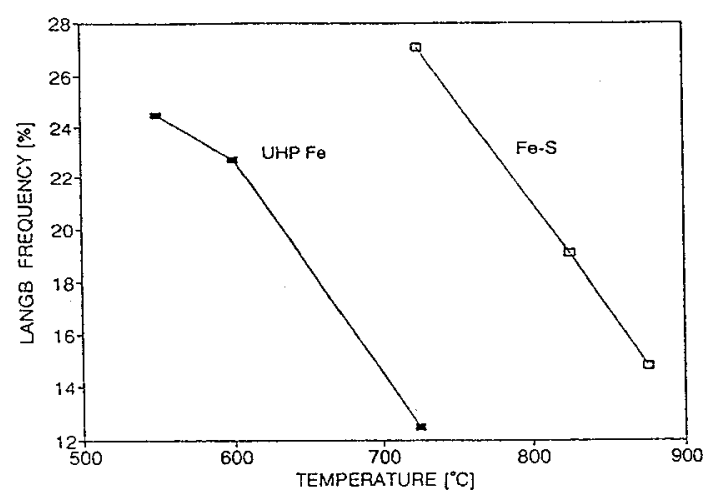

Figure 5: The influence of the annealing temperature on the low angle boundaries frequency for UHP iron and $\mathrm{Fe}-\mathrm{S}$ alloy.

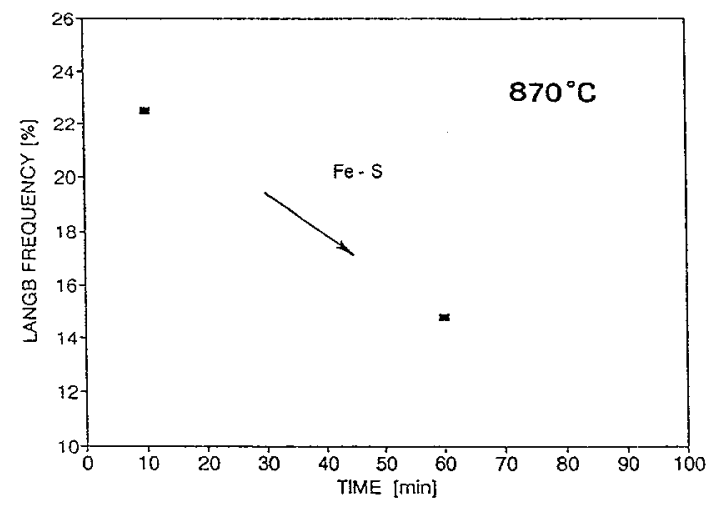

Figure 6: The inflence of the annealing time on the low angle boundaries frequency for Fe-S alloy.

\subsection{Sulphur segregation on the grain boundaries}

The effects of temperature and carbon addition on the sulphur intergranular segregation in Fe-S were examined by means of AES. The analyses were performed on the intergranular fracture surface, obtained by impact fracture, inside of the high vacuum chamber of the spectrometer. Two alloys were investigated (Table 2): a binary Fe-70ppmS (Fe-S, samples 6,7) and a ternary Fe-30ppmC-65ppmS (Fe-30C-S, samples 10,11 ). The low carbon content of the later ternary alloy was especially designed in order to: 1) favor intergranular fracture for AES investigation (fracture of the Fe-150ppmC-75ppmS composition (FeC-S, Table.1, sample 9) is completely transgranular); 2) ensure that the effect of temperature on the segregation could be examined in the temperature range where both carbon and sulphur additions are in solid solution. Otherwise, the presence of intergranular precipitates affects the measurements of the concentration of segregated atoms. In fact at a carbon content of $150 \mathrm{ppm}$ below $750{ }^{\circ} \mathrm{C}$ carbon is in solid solution, but $75 \mathrm{ppm}$ sulphur is over the solubility limit and thus part of sulphur is precipitated at the grain boundaries. Above $750{ }^{\circ} \mathrm{C}$ the iron containing $150 \mathrm{ppm}$ of carbon became partially austenitic. At $30 \mathrm{ppm}$ of carbon the phase transformation temperature is situated above $870{ }^{\circ} \mathrm{C}$ i.e. higher than the sulphur solubility limit temperature $\left(820^{\circ} \mathrm{C}\right)$, so that solid solution Fe-C-S alloys are feasible. The samples undergo almost exactly the same theromechanical treatment as for the CGBD analyses Fig.1, with the difference that the $\mathrm{Fe}-30 \mathrm{ppmC}-65 \mathrm{ppmS}$ alloy was transformed by forging instead of hydrostatic extrusion. Segregation was examined for two annealing temperatures: 820 and $870{ }^{\circ} \mathrm{C}$. Both temperatures are situated in the solid solution range for carbon and for sulphur.

\subsection{Fe-S alloy}

The levels of the intergranular atomic concentrations, estimated according to the Palmberg method [15], are indicated in Table 2 . The segregation clearly decreases with temperature in the range 820 to $870^{\circ} \mathrm{C}$.

\subsubsection{Fe-C-S alloy}

The addition of about $30 \mathrm{ppm}$ of carbon to the Fe-S alloy, for both annealing temperatures, gives lower segregation levels than in the pure Fe-S alloy. Clearly, the lower segregation level is a consequence of the site competition of carbon and sulphur segregation on the grain boundaries. Earlier AES investigations have also shown the existence of a competition between sulphur and carbon segregation on iron surfaces [16]. First carbon segregates to the surface and is then very quickly replaced by sulphur atoms. Certainly at 
the grain boundaries the same kind of competition take place, but the residual level of carbon at the grain boundaries is low and difficult to reveal by AES analysis. The background fluctuation level in the AES spectra corresponds to few percent of residual carbon concentration in the grain boundaries.

\begin{tabular}{|c|c|l|c|c|}
\hline ALLOY & $\begin{array}{c}\text { Sample } \\
\mathrm{N}^{\circ}\end{array}$ & $\begin{array}{l}\text { Annealing } \\
\text { Temp/time }\end{array}$ & $\begin{array}{c}\text { gb S } \\
\text { [at \%] }\end{array}$ & $\begin{array}{c}\text { LANGB } \\
\text { Freq [\%] }\end{array}$ \\
\hline \multirow{2}{*}{ Fe-S } & 6 & $820^{\circ} \mathrm{C} / 1 \mathrm{~h}$ & 70 & 19.1 \\
\cline { 2 - 5 } & 7 & $870^{\circ} \mathrm{C} / 1 \mathrm{~h}$ & 48 & 14.8 \\
\hline \multirow{2}{*}{$\mathrm{Fe}-30 \mathrm{C}-\mathrm{S}$} & 10 & $820^{\circ} \mathrm{C} / 1 \mathrm{~h}$ & 17 & 10.6 \\
\cline { 2 - 5 } & 11 & $870^{\circ} \mathrm{C} / 1 \mathrm{~h}$ & 26 & 12.5 \\
\hline
\end{tabular}

Table 2: Grain boundary sulphur concentration ("gbS") and low angle boundaries frequency ("LANGB Freq").

One can also notice that the sulphur segregation level in the ternary Fe-30C-S alloy seems to increase with increasing temperature, contrary to the behaviour of the binary $\mathrm{Fe}-\mathrm{S}$ alloy, suggesting a temperature dependent redistribution between carbon and sulphur atoms segregated at the grain boundaries.

The lower sulphur segregation level in the ternary, low carbon Fe-30C-S alloy is associated with lower fractions of LANGB than in the binary Fe-S at $820^{\circ} \mathrm{C}$ and $870{ }^{\circ} \mathrm{C}$ (Table.2). The effect of carbon on the LANGB population is thus relatively strong, because only $30 \mathrm{ppm}$ of carbon is sufficient to modify the CGBP.

\section{DISCUSSION}

Concentrations as low as $70 \mathrm{ppm}$ for sulphur and $30 \mathrm{ppm}$ for carbon are able to produce significant modifications of the CGBP. The effect of these impurities on the CGBP in ultra high purity iron thus appears to be relatively strong. This seems to be an important and very promising result from the point of view of controlling polycrystal properties by grain boundary control. Thus appropriate alloying and heat treatments could be used to obtain the desired CGBP. It may be interesting to undertake further studies to investigate the effect of other metallic or nonmetallic substitutional or interstitial additions on the CGBP. It should be emphasized here that, as shown in the present work, only the use of UHP alloys provides unequivocal results without being masked by residual impurities.

There are two important effects revealed in this work: 1) sulphur increases the population of LANGB in iron up to almost twice as high as that of pure iron; 2) the addition of only $30 \mathrm{ppm}$ of carbon to the iron doped with sulphur decreases the fraction of LANGB and thus suppresses the effect of sulphur. The possible mechanisms of both effects are discussed below.

\subsection{The role of sulphur}

It seems that a high frequency of LANGB is not an inherent property of $\mathrm{Fe}-\mathrm{S}$ alloys due to the preferential orientation of recrystallization nuclei. The trace additions atoms present in iron influence the CGBD rather during primary recrystallization and subsequent grain growth. In fact, similarly high frequencies of LANGB were also observed in pure iron, but for lower recrystallization temperatures (Fig. $5-550^{\circ} \mathrm{C}$ ). The LANGB frequency in iron decreases with the increasing temperature. The same effect occurs in iron doped with sulphur, but is shifted towards higher temperatures. This means that the influence of sulphur should be interpreted in terms of its effect on the kinetics of LANGB elimination. The analysis of the effect of annealing time also supports this hypothesis, Fig.6: The initially high fraction of LANGB in the Fe-S alloy decreases with annealing time as a result of their progressive elimination. Sulphur strongly inhibits recrystallization [17] and grain growth, Fig.2, and in this way stabilizes the microstructure with the high frequency of LANGB formed during primary recrystallization. As a higher proportion of LANGB is also observed for recrystallization temperatures situated in the solid solution range (above $820^{\circ} \mathrm{C}$ ) one can suppose that sulphur acts by a solute atom dragging effect on the migrating grain boundaries rather than by 
a pinning effect of sulfide precipitates. We think that the relative influence of sulphur may be correlated to the segregation level, which should reflect the tendency of sulphur atoms to interact with the grain boundaries. As a consequence, the frequency of LANGB should also depend on the bulk sulphur content and the annealing temperature. In fact the decrease of the LANGB frequency produced at higher temperatures is associated with a lower segregation level, Table.2. Obviously, weakening the sulphur interaction with the migrating boundaries is coupled with an improvement of their intrinsic mobility at higher temperatures. In fact it seems difficult to establish the respective parts contributed by each of these phenomena.

\subsection{The role of carbon}

Although trace carbon additions do not seem to influence the LANGB population in pure iron at $725^{\circ} \mathrm{C}$, this probably occurs at lower temperatures where the grain boundary mobility is lower. Actually carbon atoms interact with migrating grain boundaries even at $725^{\circ} \mathrm{C}$ as shown by the finer grain size in $\mathrm{Fe}-\mathrm{C}$ alloy than in pure iron. However, this inhibition of grain boundary migration is not sufficient to stabilize the initial recrystallized microstructure with a high frequency of LANGB.

\subsection{The role of carbon in Fe-C-S alloys}

The role of carbon in the ternary Fe-S-C alloys seems to be quite complex. The disappearance of the effect of sulphur on the fraction of LANGB is certainly related to the reduced sulphur segregation level observed in this alloy (Table.2) compared with the binary alloy. The decrease of sulphur atom concentration in the grain boundaries is associated with a higher mobility and consequently extensive grain growth and results in more rapid elimination of LANGB boundaries.

Carbon reduces the influence of sulphur not only by decreasing the segregation, but also since it tends to segregate first [16], one can suppose that primary recrystallization and perhaps the early stage of grain growth is controlled by the interaction with carbon atoms. As a consequence, in this stage of annealing the ternary Fe-C-S alloy behaviour is similar to that of the binary Fe-C alloy. In the case of binary the Fe-C alloy carbon is not a very efficient inhibitor of recrystallization [17] and grain growth (Fig.2) and thus no effect on the LANGB fraction is observed at higher temperatures.

One can also notice that, in contrast to the binary Fe-S alloy, the ternary Fe-30C-S alloy exhibits a stable level or even a slight increase of the LANGB fraction at between 820 and $870{ }^{\circ} \mathrm{C}$ and this seems to correlate with the increased segregation.

\section{CONCLUSIONS}

- 1). Trace quantities as low as $70 \mathrm{ppm}$ of sulphur and $30 \mathrm{ppm}$ of carbon are able to produce a significant modification of the CGBP in UHP iron alloys.

- 2). Sulphur increases the proportion of LANGB in iron to double that of UHP iron. The addition of carbon to the iron - sulphur alloys suppresses this effect.

- 3). The high frequency of LANGB in Fe-S alloys does not seem to be an inherent property of this kind of alloy, but is interpreted in terms of its kinetic effect. Sulphur strongly inhibits recrystallization and grain growth and hence stabilizes the microstructure with the high frequency of LANGB formed during primary recristallization. Sulphur is thought to act by the dragging effect of solute atoms segregated to the grain boundaries.

- 4). The reduced frequency of the LANGB produced by the addition of carbon to the Fe-S alloy seems to be related to the decrease of sulphur segregation resulting from a competition of carbon and sulphur segregation.

- 5). The influence of the chemical composition on the CGBP may be considered as a potential method for controlling polycrystal grain boundary dependent properties. It may be interesting to perform further studies in order to examine the influence of other metallic and non metallic, substitutional and interstitial additions.

\section{Acknowledgements}

The authors are grateful to Prof. M.W. Grabski (Warsaw University of Technology) for several fruitful discussions. 


\section{References}

[1] T. Watanabe, Mater. Sci. Forum Vol.46 198925.

[2] W.A. Swiatnicki, M.W. Grabski, Mater. Sci. Eng. 100 (1988) 85-100.

[3] T. Watanabe, Mater. Sci. Eng. A166 (1993) 11-28

[4] T. Watanabe, Res. Mechanica 11 (1984) 47.

[5] K.T. Aust and G. Palumbo, Proc. Int. Symp. on Advanced Structural Materials, Montreal, Canada, August 22-26 1988, 9, CIM Proc,, Pergamon Press, Toronto, 1989, p.215.

[6] B. Elm'Rabat, Ph.D. thesis, Université Paris XI, Paris, 1986.

[7] C. Pichard, J. Rieu and C. Goux, Metall. Trans. 7A (1976) 1811.

[8] C. J. McMahon, Jr. Z. Metallkde. 75 H7 (1984) 496.

[9] C. A. Hippsley, Acta Metall. 35, 10, (1987) 2399.

[10] E.P. George, P.L. Li and D.P. Pope, Acta Metall. 35 (1987) 2471-2495.

[11] M. Tacikowski, G. A. Osinkolu and A. Kobylanski, Acta Metall. 364 (1988) 995.

[12] S. Suzuki, S. Tanii, K. Abiko and H. Kimura, Metall. Trans. 18A (1987) 1109.

[13] M. Tacikowski, Ph.D. thesis, EMSE-INPG, Saint-Etienne, France, 1986.

[14] A. Akef, Ph.D. thesis, EMSE-INPG, Saint-Etienne, France, 1993.

[15] L.E. Davies, N.C. Mc Donald, P.W. Palmberg, G.E. Riach, R.E. Weber,"Handbook of Auger Electron Spectroscopy", Physical Electronics Industries, Eden Prairie, Minesota, 1976.

[16] G. Saindrenan, M. Tacikowski unpublished data.

[17] M.Tacikowski unpublished data. 